\title{
EUROPEAN UNION POLICY-MAKING ON ROBOTICS AND ARTIFICIAL INTELLIGENCE: SELECTED ISSUES
}

\author{
Thomas Kirchberger*
}

\begin{abstract}
Summary: This article uses the recently issued report on civil law rules on robotics by the European Parliament's Committee on Legal Affairs as an anchoring point. After a brief overview of the topic's socio-economical background, it contains an attempt to define and explain artificial intelligence. By examining the role of autonomous machines in the workforce, it gives an overview of the most pressing questions the future of labour might bring. One closely connected issue is the still unanswered question of liability regarding artificially intelligent robots, which will most certainly have to be tackled by future policy makers. Another such open question is a new approach on creativity, where the key phrase "own intellectual creation" might have to be redefined in order to cover copyrightable works produced by computers. Lastly, the European Parliament's Report on Robotics calls for a new European Agency for Robotics and Artificial Intelligence is addressed.
\end{abstract}

\section{Introduction}

We undoubtedly live in turbulent times. New industrial phenomena are re-shaping our economy and what we think of production, the workforce, and employment. Some of these new phenomena could potentially have - further - drastic impacts on society and it is our duty as scientists to analyse and interpret these developments in order to find new approaches on how to deal with them.

This article hopes - amongst other things - to shed some light on how automation will change our workplaces and our society as a whole in the years to come. Most jobs carried out by humans today are going to be obsolete in either a few years or in at least a few decades. The sales of robots are ever increasing and annual patent filings for robotics technology have tripled over the last decade. While some industries will see an increase in such technology being used, others might have to rearrange themselves completely. One of the main areas affected is going to be transportation, where artificial intelligence is on the brink of going mainstream, posing new questions on liability.

\footnotetext{
Dr Thomas Kirchberger wrote this article as research assistant at the Institute of Public International Law, Air Law and International Relations at the Johannes Kepler University Linz. As of December 2017, he started working at the Staff Department for Communication and Public Relations in the Austrian Ministry of Justice.
} 
Robots such as self-driving cars and all other forms of artificial intelligence being put into practice will inevitably rely on massive amounts of data. Applications and appliances will communicate both with each other and with data centres, most probably while transferring big amounts of data laden with personal information about their users. It is doubtful that the current legal framework on data protection and ownership is sufficient to tackle these upcoming challenges.

The latest developments in automation and robotics are owed to the rapid evolution of artificial intelligence. Instead of waiting and seeing, the European Union has decided to pioneer and venture into this largely uncharted territory with the European Parliament's Committee on Legal Affairs issuing a report ${ }^{1}$ on civil law rules on robotics to the Commission.

One of the goals of this contribution is to shed some light on the European Union's venture into this largely uncharted territory, which I attempt to do by devoting a comparatively large section to the topic's socio-economic background. Further, I elaborate on selected key topics, which are wholly independent of each other. Besides delineating the call for a new European Agency for Robotics and Artificial Intelligence, I examine liability issues in the realm of self-driving vehicles as well as a new take on creativity, where the key phrase 'own intellectual creation' might have to be redefined in order to cover copyrightable works produced by computers.

\section{Industry 4.0}

Fascinating new technologies are used as a discussion starter to talk about an imminent or already progressing industrial revolution. ${ }^{2}$ 'Industry $4.0^{\prime}$ as a term was originally coined by the German government ${ }^{3}$ and is now widely used to describe the latest industrial revolution humanity has witnessed - or better - supposedly is witnessing right now. The first

\footnotetext{
1 European Parliament, Committee on Legal Affairs, Draft Report with recommendations to the Commission on Civil Law Rules on Robotics, 2015/2103 (INL). The draft report was discussed in the Parliament's plenary sitting on 27 January 2017 and is now available as a report including the opinions of the Committees on Transport and Tourism, on Civil Liberties, Justice and Home Affairs, on Employment and Social Affairs, on the Environment, Public Health and Food Safety, on Industry, Research and Energy, and on the Internal Market and Consumer Protection, A8-0005/2017 (hereinafter 'Robotics Report').

2 'A Third Industrial Revolution' The Economist (London, 21 April 2012) <www.economist. com/node/21552901> accessed 20 May 2017; Chris Anderson, Makers - Das Internet der Dinge: die nächste industrielle Revolution (Hanser 2013) 29ff, 101ÓH; Neil Gershenfeld, 'How to Make Almost Anything: The Digital Fabrication Revolution' (2012) 91(6) Foreign Affairs 43; Bundesministerium für Bildung und Forschung, Zukunftsprojekt Industrie 4.0 <www.bmbf.de/de/19955.php> accessed 20 May 2017.

3 In 2011, the German Ministry of Education and Research first used the term when it started a project promoting the computerisation of manufacturing. Bundesministerium (n 2).
} 
ever industrial revolution began in Britain in the late $18^{\text {th }}$ century with the mechanisation of the textile industry by introducing looms powered by hydraulic energy and steam power. This led to the invention of the spinning machine and the power loom, which rang in the age of mechanical production. The second industrial revolution began in America in the late $19^{\text {th }}$ century with the introduction of electrically powered production lines in Cincinnati's slaughterhouses and in the early $20^{\text {th }}$ century the assembly line for Ford's 'Model T', which paved the way for the era of mass production. ${ }^{4}$ The third industrial revolution is said to have happened in the second half of the $20^{\text {th }}$ century with the widespread introduction of electronics and information technology for the further automation of production. ${ }^{5}$ This is the age we are living in right now or, as some ${ }^{6}$ might argue, the one that is about to run out in view of the impending or even already happening next industrial revolution. There seems to be no consensus amongst scholars on the correct numbering of the latest industrial revolution. While most seem to call it the "third" one, I argue that it is the fourth, based on the steps of industrialisation mentioned above. ${ }^{8}$

In order to illustrate how production methods have changed over the course of these various industrial revolutions, a car might serve as the best example. While the second industrial revolution focused on the industrialisation of production facilities, the fourth industrial revolution focuses on the product. As Knyrim and Treml point out, Henry Ford famously announced the Model T's revolutionary production method by saying that 'any customer can have a car painted any colour that he wants so long as it is black'. ${ }^{9} \mathrm{He}$, of course, had a simplified and streamlined production process in mind, as he later wrote in his autobiography. In contrast, today's consumers can choose from a variety of options for every single car model and in many cases can determine not only the

\footnotetext{
$4 \quad$ Economist (n 2); Bill Bryson, One Summer: America 1927 (Transworld Publishers 2013) $256 \mathrm{ff}$.

5 'Industrie 4.0: Das neue Zeitalter der Produktion' (Austria Innovativ, issue 4, 2014 ) 42.

6 As an example, researchers at the Johannes Kepler University Linz are examining the impact Industry 4.0 might have on the working environment. With Industry 4.0 being a model for technological and organisational development, it might also change the way the future factory looks. The most dystopian vision of a deserted shop floor occupied only by robots - eventually rendering humans useless - is thankfully still rather far-fetched. Christian Savoy, “Schöne neue Arbeitswelt?” JKU-Projekt untersucht Zukunft der Arbeit' 2015 <www.jku.at/content/e213/e63/e58/e57?apath=e32681/e262488/ e276794/e278515> accessed 20 May 2017.

7 The Economist (n 2). One author, however, even calls it the second, upcoming revolution, which I cannot agree with. See Rudolf Taschner, '2017 - ein schreckliches, ein gutes Jahr?' (Vereinigung österreichischer Wirtschaftstreuhänder, issue 1, 2017) 15.

8 The same reasoning can be found in Rainer Knyrim and Boris Treml, 'Industrie 4.0 Auswirkungen auf Datenschutz und Arbeitsrecht' (Datenschutz konkret, issue 5, 2016) 103.

9 Henry Ford, My Life and Work (first published 1922, Project Gutenberg 2005) <www. gutenberg.org/cache/epub/7213/ pg7213-images.html> accessed 20 May 2017.
} 
chassis' colour but also personalise the car's interior. It is no longer the manufacturing machine determining the product's features but rather the product telling the manufacturing machine which version of it should be produced. ${ }^{10}$

Beyond that, Industry 4.0 stands for a number of changes that will affect how our economy works. Digital fabrication ${ }^{11}$ will lead to the more direct involvement of consumers in production processes and facilitate small-batch production as compared to the now prevalent mass production. Other aspects of Industry 4.0 include phenomena known under certain catchwords. Some examples would be 'smart factories', which are quite closely related to digital fabrication, as they offer the possibility for consumers to directly order individualised products, bypassing the established channels of development and distribution. Smart factories use the tools of digital fabrication ${ }^{12}$ and feature intelligent machinery, autonomously detecting their need for production material or servicing by highly qualified operators. Another catchword describes so-called 'smart grids', which stand for the interconnection of devices in smart electricity networks. This is a prerequisite for them to go online in order to be remotely controlled or even autonomous. In exchange for this, new vulnerabilities are coming into existence, which could make energy grids susceptible to hacking attacks, for example by turning all devices on at once and thus provoking a grid failure. The said devices will be part of the 'internet of things', which, in essence, describes the increasing depletion of traditional computers and the growth of intelligent devices. These products ideally operate practically unnoticed by humans and are

10 Knyrim and Treml (n 8) 103-104.

11 The revolutionary aspect of digital fabrication is the possibility it offers, namely to produce high quality goods in small batches at reasonable costs. Complexity and quality do not cost extra, as it makes no difference to the machine(s) during the production process. Digital fabrication allows - or at least will allow - individuals to design and/or produce on demand anywhere and at any time. The revolutionary aspect lies in the possibility of using more and more affordable tools and use them to transform data into objects - and the other way around. A prerequisite and vital aspect of the next industrial revolution lies in the broad and direct access to its means of production. Cf Carl Bass, 'The Past, Present and Future of 3-D Printing' The Washington Post (Washington, 24 August 2011) <www. washingtonpost.com/national/on-innovations/the-past-present-and-future-of-3-d-printing/2011/08/21/gIQAg4fJZJ_story.html> accessed 20 May 2017; Neil Gershenfeld, 'How to Make Almost Anything - The Digital Fabrication Revolution' (2012) 91(6) Foreign Affairs 43ff.

12 To name just a few of these technologies, 3D-printers, 3D-scanners, laser cutters and CNC-machines in all forms and sizes come to mind. From all of these, 3D printing may be one of the most widely discussed. The fascination with this increasingly important technology has led to its coverage not only in technology magazines but also in detailed articles in newspapers or even lifestyle magazines. Leander Bruckbög, '3D-Druck: Wichtiger als das Internet?' Oberösterreichische Nachrichten (Linz, 3 February 2013); 'Benvenuti nella terza dimensione' (Gentlemen's Quarterly, issue 171, 2013) 40; Leander Bruckbög, '3D-Drucker werden massentauglich - Aber wie funktioniert das eigentlich?' Oberösterreichische Nachrichten (Linz, 18 January 2014). 
designed to support them. An example would be a refrigerator autonomously ordering and replacing groceries that have been consumed or a thermostat heating up a housing space on its own as soon as it senses the presence of a resident. The interconnected devices of the internet of things will create incredible amounts of data offering a multitude of possible uses - and abuses. This aspect dubbed 'big data' constitutes one of the many reasons for justified scepticism with regard to the phenomenon of Industry 4.0, which will cause the need for an abundance of security and data protection measures. ${ }^{13}$

\section{Robotics Report}

In its role as policy maker, the European Parliament is fully aware of the bundle of developments that constitute Industry 4.0. With the Report on Robotics issued by its Committee on Legal Affairs, the Parliament shows that it is not only keeping up with the times but is also being expressively foresighted. As jurists, we all know that - unlike the said report - most national and international legal policies tend to be reactions to new trends and developments in technology and society. It is quite refreshing to observe that the report features a long list of recitals constituting the basis of the recommendations to the Commission. The report was issued according to article 46 of the European Parliament's Rules of Procedure ${ }^{14}$ which itself is based on article 225 TFEU. ${ }^{15}$ The latter allows the European Parliament - acting by a majority of its members - to request the Commission to submit any appropriate proposal on matters on which it considers that a Union act is required for the purpose of implementing the Treaties.

The Legal Affairs Committee emphasises the fascination humanity has seemingly always had with the possibility of building intelligent machines, especially when they appear in a human-like form. ${ }^{16}$ The report underlines the impending industrial revolution, which will feature sophisticated robots, bots, androids and other manifestations of artificial intelligence which will eventually have massive effects on society and therefore create the need for legislation that is appropriate on the one

13 'Industrie 4.0: Das neue Zeitalter der Produktion' (Austria Innovativ, issue 4, 2014), 42-44; Alfred Bankhamer and Norbert Regitnig-Tillian, 'Industrie 4.0 - Die Crux mit der Sicherheit' (Austria Innovativ issue 1, 2015) 10-14.

14 European Parliament, Rules of Procedure (2014) <www.europarl.europa.eu/sipade/ rulesleg8/ Rulesleg8.EN.pdf> accessed 20 May 2017.

15 Consolidated Version of the Treaty on the Functioning of the European Union [2016] OJ C202/47.

16 Robotics Report (n 1) recital A, where vivid references to creatures such as Mary Shelley's Frankenstein's monster, the myth of Pygmalion, the Golem of Prague or the robot of Karel Čapek are made. 
hand and does not hinder innovation on the other. This involves the creation of a flexible and generally accepted definition of 'robot' and 'artificial intelligence'. ${ }^{17}$

\section{Artificial Intelligence}

While the report calls for a definition of artificial intelligence in recital $\mathrm{C}$, it does not attempt to define it, as this will most probably be the Commission's task. In order to grasp the concept, I took it upon myself to educate myself on the subject. ${ }^{18}$

For thousands of years, we as humans have tried to understand how we think, how a 'handful of matter can perceive, understand, predict, and manipulate a world far larger and more complicated than itself'. The field of artificial intelligence goes further: it not only attempts to understand but rather to build intelligent entities. Artificial intelligence is an enormous scientific field encompassing a wide range of subfields, such as a general one devoted to learning and perception, to specific ones concerned with proving mathematic theorems, diagnosing diseases or driving cars on crowded streets. ${ }^{19}$

There is not one specific ways to define artificial intelligence but rather four main approaches, which focus on different specific aspects, such as the thought process, reasoning, and behaviour. These aspects are then measured in terms of fidelity to either human performance or ideal performance. ${ }^{20}$ The former, human-centred approach relies on empirical science, involving observations and hypotheses about human behaviour. The latter, rationalist approach involves a combination of mathematics and engineering. In total, there are four main approaches to what artificial intelligence is. First, the Turing Test approach, which focuses on artificial intelligence acting humanly. This concept is more than 60 years old and involves the computer's capabilities of natural language processing to enable it to communicate successfully, knowledge representation to store what it knows or hears, automated reasoning to use the stored information to answer questions and to draw new conclusions, as well as machine learning to adapt to new circumstances and to detect and extrapolate patterns. A computer passes this test if a human interrogator, after posing some written questions, cannot tell whether the written re-

\footnotetext{
17 Robotics Report (n 1) recitals B and C.

18 At this point I would like to thank Thomas Unterthiner from the Institute of Bioinformatics of the Johannes Kepler University Linz for providing me with a basic insight into the topic and pointing out the most important sources.

19 Stuart Russel and Peter Norvig, Artificial Intelligence - A Modern Approach(3rd edn, Pearson 2010) 1 .

20 Ideal performance is called rationality. A system is rational if - based on its knowledge it does the 'right thing'.
} 
sponses come from a person or a computer. This approach was extended to the total Turing Test, which includes a video signal, allowing the interrogator to test the computer's perceptual capabilities. In order to pass, it relies on computer vision to perceive objects and robotics to manipulate objects and move about. ${ }^{21}$

Another approach focuses on cognitive modelling and the computer's capability of thinking humanly. One approach focuses on the 'law of thought' and examines whether a computer can think rationally. Lastly, yet another approach examines whether a computer agent who operates autonomously, perceives its environment, adapts to change and creates and pursues goals, acts rationally so as to achieve the best outcome. ${ }^{22}$ This shows that there is no universal definition of artificial intelligence, a fact the Commission will have to take into account. I assume that an attempt to define artificial intelligence will rely heavily on the total Turing Test approach, as it most heavily depends on the interaction between humans and machines.

As artificial intelligence could very probably - sooner or later - surpass human intelligence, it is crucial to build safeguards and the possibility of human control and verification into the process of automated and algorithmic decision-making. When it comes to regulatory action, the Union seeks to follow the example of some third countries standing at the forefront of robotics and artificial intelligence development, such as the United States, Japan, China and South Korea. An early unitary approach to appropriate regulatory standards would certainly benefit the internal market, especially in regard to enhanced competitiveness with these economic powers, and ensure that the Union will not have to adopt standards created abroad. Underlining the importance ${ }^{23}$ of not stifling innovation, the report also underlines the importance of a gradualist, pragmatic and cautious approach concerning future initiatives on robotics and artificial intelligence. ${ }^{24}$

\subsection{Automation and Machine Learning}

One issue that I have not mentioned in the short summary on the history of industrialisation above is one key aspect of our industry as we

\footnotetext{
21 Russel and Norvig (n 19) 2-3.

22 ibid, 3-4.

23 The Robotics Report here goes so far as to refer to the fathers of the European Union, Robert Schuman and Jean Monnet, with the famous quote 'Europe will not be made all at once, or according to a single plan. It will be built through concrete achievements which first create a de facto solidarity'. Fondation Robert Schuman, 'Declaration of 9 May 1950 delivered by Robert Schuman’ (2011) 204 European Issue <www.robert-schuman.eu/en/ doc/questions-d-europe/qe-204-en.pdf> accessed 20 May 2017.

24 Robotics Report (n 1 ) recitals $\mathrm{Q}$ to $\mathrm{T}$, and $\mathrm{X}$.
} 
know it today: automation. Automation is already ubiquitous in industrial production and has been for a long time now. We are all familiar with the concept of a big machine hall full of brightly coloured robotic arms that pick up, position and assemble or weld pieces in order to produce, say, car frames or electrical appliances.

However, this picture is now being extended by a new aspect called 'machine learning', which can be considered one aspect of artificial intelligence. Until recently, automation was limited to the exact tasks humans told machines to do. A robot was programmed to go to a certain position, execute a command like closing its claw in order to grab an object, then go to another position and execute another command. If a problem occurred, the robot was unaware of it and executed the command regardless of whether the object it should pick up was there or not or risked being damaged by the robot. Human intervention was essential to ensure that the assembly line was running smoothly.

Then, robots were taught to recognise these anomalies. By giving them sensors and cameras, the robot could replace the human in the above-mentioned example and re-align the parts it should grab by itself. This seemingly simple and logical improvement, however, requires even more complex programming and a higher level of computing power. As technology advanced, so did the robots' capabilities, rendering the human job of supervising the assembly line obsolete.

With the invention of true machine learning, robots can now be taught to do even more complex tasks. Machine learning can be considered part of the whole umbrella term of artificial intelligence and deals with those aspects of automation where machines are not only taught to execute certain tasks, but learn how to do them on their own. These learning mechanisms are based on monitoring how humans carry out certain tasks, analysing databases or drawing logical conclusions, to name just a few options. True machine learning was not possible until recent times, when computers - or better, their processors and data storage devices became fast and powerful enough to process the vast quantities of data required for machine learning.

\subsection{Smart Robots}

While the Robotics Report does not attempt to define smart robots by itself, it uses this expression and lists a number of characteristics that should be regarded in its definition. Interestingly, the report contains two similar lists and approaches in separate parts of the report, whose bullet points include aspects such as the robot's capacity to acquire autonomy through sensors and/or by exchanging data with its environment and the analysis of those data, the capacity to self-learn through experience 
and interaction, the capacity to adapt its behaviour and actions to the environment, at least a minor form of physical support and, lastly, the absence of life in the biological sense. ${ }^{25}$ This leads to the conclusion that a smart robot will have to be considered as a machine autonomously operating based on artificial intelligence.

\section{Liability}

\subsection{Robots and liability}

It is quite unusual for a legislative proposal to read like a science fiction novel. Quite refreshingly, the report introduces its thoughts on liability with some general principles that apply to robotics. It starts by referencing Isaac Asimov's three laws of robotics which he later extended by a fourth - or zeroth - law:

(1) A robot may not injure a human being or, through inaction, allow a human being to come to harm;

(2) A robot must obey the orders given it by human beings except where such orders would conflict with the First Law;

(3) A robot must protect its own existence as long as such protection does not conflict with the First or Second Laws;

(0) A robot may not harm humanity, or, by inaction, allow humanity to come to harm. ${ }^{26}$

The Robotics Report directs these laws to the designers, producers and operators of robots. It also expressively includes robots assigned with built-in autonomy and capable of self-learning, since those laws cannot be converted into machine code. In addition, it calls for the establishment of basic ethical principles to be respected in the development, programming and use of robots and artificial intelligence. ${ }^{27}$

Furthermore, the Robotics Report attempts to draft a Code of Ethical Conduct for Robot Engineers and aims a number of clauses at robot designers. This long 'license' reminds designers to take into account the European values of dignity, autonomy and self-determination, freedom and justice before, during and after the process of design, development and delivery of such technologies, including the need not to harm, injure, deceive or exploit (vulnerable) users and urges them to introduce

25 Robotics Report (n 1) annex, ep 1.

26 Robotics Report (n 1) recital U wfr.

27 These principles should be incorporated into Union regulations and codes of conduct, with the aim of shaping the technological revolution, thus serving humanity and ensuring that the benefits of advanced robotics and artificial intelligence are broadly shared, while as far as possible avoiding potential pitfalls. Robotics Report (n 1) recital W. 
trustworthy system design principles across all aspects of a robot's operation, for both hardware and software design, and for any data processing on or off the platform for security purposes.

One major question in the research on artificial intelligence is whether we are capable of truly controlling it. In theory, artificial intelligence could, once unleashed, surpass human intelligence, thus outsmarting us in every aspect. The report therefore urges designers to integrate obvious opt-out mechanisms - also known as kill switches - in order to ensure ongoing control over these machines. However, and this is a rather philosophical thought, once artificial intelligence surpasses humanity's cognitive capabilities, it might find a way to work around these kill switches or to manipulate humans not to activate them. This is why designers - at least for now - should analyse the predictability of a human-robot system by considering uncertainty in interpretation and action and possible robotic or human failures, which also means to ensure that robots are identifiable as robots when interacting with humans. ${ }^{28}$

As the list of recommendations to the robots' designers contains many issues, I include only one more aspect. Designers should safeguard the safety and health of those interacting and coming in touch with robotics, given that robots as products should be designed using processes which ensure their safety and security. These last aspects are also reflected in another licence included in the report, which is aimed at the users of robotic systems. Some of the items included in this list are based on common sense, some are based on legal principles, and some will potentially have to be regarded in the drafting of future legal norms concerning the use of robotic systems. On the one hand, it assures users that they are permitted to make use of a robot without risk or fear of physical or psychological harm, while having the right to expect a robot to perform any task for which it has been explicitly designed. On the other, users are not permitted to use a robot in any way that contravenes ethical or legal principles and standards, or to collect, use, or disclose personal information without the explicit consent of the data subject. Lastly, and this might become an issue as well, users are not permitted to modify any robot to enable it to function as a weapon. ${ }^{29}$

\footnotetext{
28 Robotics Report (n 1) annex. For those interested in this specific question, I highly recommend the TED Talk by Sam Harris on the topic 'Can We Build AI without Losing Control over It?' Sam Harris, 'Can We Build AI without Losing Control over It?' (TED Talk 2016) <www.ted.com/talks/sam_harris_can _we_build_ai_without_losing_control_over_ it?language $=$ en $>$ (video link) accessed 20 May 2017; <www.ted.com/talks/sam_harris_can_ we_build_ai_without_losing_control_over_it/> (transcript link) accessed 20 May 2017.

29 In the summer of 2015 , the greatest minds in the field of artificial intelligence, robotics, computer science and in a great number of other scientific disciplines signed an open letter expressing the wish for a ban on offensive autonomous weapons. The thousands of signatories include names such as Stuart Russel, Peter Norvig, Stephen Hawking, Elon Musk,
} 
In regard to liability specifically, the report emphasises the impressive technological advances being made in the last decade. It focuses on the fact that - apart from being able to perform activities which used to be typically and exclusively human - robots can now also be equipped with certain autonomous and cognitive features. This aspect described above as 'machine learning' allows machines to learn from experience and take quasi-independent decisions, which makes them increasingly similar to agents that interact with as well as alter their environment. ${ }^{30}$

The more autonomous robots become, the less they will be able to be considered as simple tools in the hands of persons. Depending on the limitations set by the level of sophistication of their technical design, these machines could reach a level of independence that would require a new look at legal responsibility. In the - certainly undesirable - case of a robot's harmful action, the question of liability might not only focus on persons involved in the robot's design, construction or programming but might extend to the robot itself. Under the current legal framework, robots themselves cannot be held liable for acts or omissions that cause damage to third parties. Our existing liability laws cover cases where the damage caused by a machine's act or omission can be traced back to a specific human agent, ${ }^{31}$ who is liable if he could have foreseen and avoided the robot's harmful behaviour. With robots' increased autonomy, the question arises about whether they can be subsumed under any existing legal category or if a new category should be created. ${ }^{32}$

As one connecting factor, the Robotics Report mentions the European product liability framework. In principle, this legal framework assures that the producer of a product is liable for a malfunction. This approach will have to be confronted with the rules governing liability for harmful actions, where the user of a product is liable for a behaviour that leads to harm. In the next section I will juxtapose these issues in the context of self-driving vehicles, a textbook example of applied artificial intelligence. ${ }^{33}$

\subsection{Self-driving vehicles}

As announced above, I attempt to shed some additional light on one particular area of application of intelligent robots: self-driving vehicles. There are many socio-economic questions that will undoubtedly have to be answered in a future where - as experts predict - most commercial

and Steve Wozniak. 'Autonomous Weapons: An Open Letter from AI \& Robotics Researchers' (Future of Life Institute 2015) < https://futureoflife.org/open-letter-autonomous-weapons/> accessed 20 May 2017; Robotics Report (n 1) annex.

30 Robotics Report (n 1 ) recital $Z$.

31 This could be the manufacturer, the operator, the owner or the user.

32 Robotics Report (n 1) recitals AA to AD.

33 ibid, recital AE. 
transport will be done by autonomous vehicles. In contrast to vehicles driving on pre-programmed routes or using artificial hints such as magnetic strips in their environment to orient themselves, autonomous vehicles have the power for self-governance. ${ }^{34}$

Again, there is no abundance of arguments that can be held against an entrepreneur who decides to substitute costly human lorry or delivery vehicle drivers with robots that can drive tirelessly for up to 168 hours a week, that do not get sick, are not entitled to a certain number of vacation days or decide to form labour unions, and, most of all, do not ask to be paid. Furthermore, self-driving vehicles are only a few steps away from changing the way we think about commuting. Researchers have been working on autonomous cars for decades, but the latest developments in artificial intelligence have allowed for truly remarkable results. For example, Google ${ }^{35}$ reported that by March 2016 its autonomous car fleet had autonomously driven a total of 2,400,000 kilometres, while the cars had been involved in only 14 crashes. Thirteen of these were caused by other - human - drivers on the road, and only one of these crashes - in slow traffic and resulting in only minor car body damage - could be blamed on the car's software. ${ }^{36}$ Alas, there has been one fatality when a Tesla Model S electric car was engaged in Autopilot mode ${ }^{37}$ and crashed into a turning tractor-trailer in May 2016, as 'neither autopilot nor the driver noticed the white side of the tractor-trailer against a brightly lit sky, so the brake was not applied'. ${ }^{38}$

Still, the advantages of self-driving vehicles are apparent. Humans tend to become distracted or tired, some text while driving, or - even worse - drink and drive. Increased reliance on autonomous vehicles

\footnotetext{
34 Panos J Antsaklis, Kevin Passino and SJ Wang, 'An Introduction to Autonomous Control Systems' (June 1991) IEEE Control Systems 5 <http://neuron-ai.tuke.sk/hudecm/ PDF_PAPERS/Intro-Aut-Control.pdf> accessed 20 May 2017.

35 Now under the roof of its parent company Alphabet. Google's self-driving car technology has since been spun-off to a new company called Waymo.

36 Google Self-Driving Car Project Monthly Report (March 2016) <https://static.googleusercontent.com/media/ www.google.com/1t//selfdrivingcar/files/reports/report-0316. pdf $>$ accessed 20 May 2017; Matt McFarland, 'For the First Time, Google's Self-driving Car Takes some Blame for a Crash' The Washington Post (Washington, 29 February 2016) <www.washingtonpost.com/news/innovations/wp/2016/02/29/for-the-first-time-googles-self-driving-car-takes-some-blame-for-a-crash/?utm_term=.94be68fbf856> accessed 20 May 2017.

37 When Tesla's Autopilot is engaged, the car can act autonomously but requires the full attention of the driver, who must be prepared to take control at a moment's notice. Autopilot should be used only on limited-access highways and is not suitable for inner-city traffic.

38 Tesla, 'A Tragic Loss' (30 June 2016) <www.tesla.com/blog/tragic-loss> accessed 20 May 2017; Danny Yadron and Dan Tynan, 'Tesla Driver Dies in First Fatal Crash while Using Autopilot Mode in San Francisco' The Guardian (London, 1 July 2016) <www.theguardian.com/technology/2016/jun/30/tesla-autopilot-death-self-driving-car-elon-musk> accessed 20 May 2017.
} 
could prevent many accidents caused by human mistakes, carelessness or wrongdoing. Being able to commute in self-driving vehicles would not only free up time which could be spent resting, working, or for leisure, but the cars' usage would also become more efficient. A typical suburban family - like the one I come from - might need to own only one car, as it might bring one family member to work and then return home on its own in order to be used by someone else. In short, this new technology will bring some evident benefits for consumers. Governments worldwide are realising this and are making available test tracks on public roads. While the United States has been considered a driving force in this trend for quite some time now, European governments are finally catching up as well. ${ }^{39}$

\subsubsection{Status quo}

The reasons for governments' hesitation are evident. What if something goes wrong? From today's perspective, the situation on the roads is simple enough. Generally speaking, only natural persons in possession of an officially issued driver's licence are allowed to drive a vehicle. ${ }^{40}$ Therefore, a self-driving car has no legal basis and is therefore not allowed to drive on public roads. In theory - as Templ notes - this also includes cars featuring assisted-drive modes, thus allowing what he calls a 'light' version of self-driving. As a consequence, in order to accomplish the legal framework for the driving of autonomous vehicles, it would be necessary to create an exception with regard to the legal obligation for a driver's licence. ${ }^{41}$

\subsubsection{Fault-based liability}

For now, liability is connected to the definition of 'driving a vehicle'. In autonomous cars, this active human action is replaced by sequential machine- and computer-operated commands. Consequently, culpability as a key element of fault-based liability disappears - or rather - is transferred to the vehicle's manufacturer. This means that instead of being able to hold a car's driver, its owner or its insurer liable, a victim will have

\footnotetext{
39 For example, Germany is already offering certain stretches on its motorways for these purposes, and Austria is trying to follow its neighbour's example. Alice Grancy and Barbara Grech, 'Ab 2016 düsen selbstfahrende Autos durch Österreich' Die Presse (Vienna, 28 August 2015) <http://diepresse.com/home/ techscience/hightech/4807819/Ab-2016-duesen-selbstfahrende-Autos-durch-Oesterreich-> accessed 20 May 2017; 'Deutschland baut Teststrecken für selbstfahrende Autos aus' (futurezone, 13 June 2016) <https: / futurezone. at/science/deutschland-baut-teststrecken-fuer-selbstfahrende-autos-aus/204.291.054> accessed 20 May 2017.

40 For Austria, Austria driver's licence law (Bundesgesetz über den Führerschein) BGB1 I $1997 / 270$ aa BGB1 I 2005/15, § 1 para 3 icw § 3 para 1.

41 Heinzl Templ, “Über “die Haftungsfrage” von selbsttätig am Straßenverkehr teilnehmenden Kfz' (Zeitschrift für Verkehrsrecht, issue 1, 2016) 13.
} 
to find someone else to hold accountable, as, in most jurisdictions, fault has to be proven by the victim. ${ }^{42}$ It will be hard to prove that a technician working for the manufacturer has made a programming error when programming the car's control software, as Templ accurately highlights. ${ }^{43}$ He also predicts that autonomous cars will be equipped with something like a 'blackbox', which keeps track of the entire vehicle's data and how they are being processed. In order to correctly analyse and interpret these data that - in the case of an accident - could help find the person at fault, new kinds of technical experts will be needed. Furthermore, a manufacturer can only be held accountable for the wrongdoing of its agents - ie technicians - under certain limited legal circumstances. ${ }^{44}$ Fully aware of these liability issues, the automobile manufacturer Volvo announced that it will take full responsibility for any accident caused by its selfdriving cars. ${ }^{45}$

Fault-based liability as a basis for the awarding of damages always depends on human action or inaction. A self-driving vehicle cannot be held accountable in the case of an accident, as no law has been broken by a human. As a consequence, fault-based liability will only have limited importance in the realm of self-driving cars. ${ }^{46}$ However, strict liability might be the solution.

\subsubsection{Strict liability}

Strict liability allows frictionless enforcement of liability claims independent of fault and unlawfulness, as it is based on the simple hazard of operating a motor vehicle. ${ }^{47}$ In order to be applicable, a self-driving car has to fulfil a motor vehicle's legal definition, which should not prove to be a problem with self-driving cars. ${ }^{48}$ This allows for the application of strict liability laws, which come into effect as soon as the motor vehicle is

\footnotetext{
${ }_{42}$ Allgemeines Bürgerliches Gesetzbuch, JGS 1811/946 aa BGB1 I 2016/43 (Austrian Civil Code) $\S 1296$.

43 Templ (n 41) 11.

44 ibid 10 (12). In Austrian civil law - to be exact $\S 1315$ of the Austrian Civil Code - the manufacturer can only be held accountable for its technicians if they have to be considered as habitually incapable or knowingly dangerous, which can be rather hard to prove.

45 'Volvo übernimmt Haftung für Unfälle selbstfahrender Autos' (futurezone, 8 October 2015) <https://futurezone.at/digital-life/volvo-uebernimmt-haftung-fuer-unfaelle-selbstfahrender-autos/157.288.679> accessed 20 May 2017.

46 Templ (n 41) 11-12.

47 Bundesgesetz vom 21. Jänner 1959 über die Haftung für den Ersatz von Schäden aus Unfällen beim Betrieb von Eisenbahnen und beim Betrieb von Kraftfahrzeugen, BGB1 1968/69 aa BGB1 I 2017/19 (Austrian Law on Civil Liability for Operators of Motor Vehicles and Railways) § 1 .

48 In Austrian law, a motor vehicle is a vehicle with intended use on roads or used on roads, which is driven by technically freed energy and not bound to tracks, even if it gets its driving energy from overhead wiring. Bundesgesetz vom 23. Juni 1967 über das Kraftfahrwesen, BGB1 1967/267 aa BGB1 I 2017/9. (Austrian Law on Motor Vehicles) § 2 para 1 no 1.
} 
being operated and causes an accident. ${ }^{49}$ In practice, this means that the car's holder can be held accountable and - should he not be the person using the car - he can take recourse on the said person.

\subsubsection{Product liability}

Lastly, Templ points out that product liability law ${ }^{50}$ might offer further remedies, as - in essence - it makes a producer liable for damages caused by defective products he produced and put on the market. ${ }^{51}$ This law's applicability will depend mostly on whether software can be regarded as a product. According to $\S 4$ of the Austrian product liability law, a product is amply defined as a 'tangible movable object', under which a self-driving vehicle can be easily subsumed. However, in all likelihood most accidents involving this technology will be caused by the car" software, which is intangible and therefore does not fulfil this legal requirement in a literal interpretation. ${ }^{52}$

The tendency to regard software as a tangible object when it is embodied on a medium goes too far, as, consequently, any information or idea made visible could be regarded as a tangible object. A doctrinal - or teleological - interpretation, however, seems to be the right solution, as product liability law was created as a tool against the dangers inherent in industrial - or mass - production. Its aim is therefore not to protect customers from products but rather from their dangerousness. Furthermore, $\S 4$ of the Austrian product liability law includes 'energy' in the product definition, which could be seen as the legislator's tendency to incorporate products that are not necessarily tangible. The Commission offered the safest way of interpretation when it was asked whether the directive on product liability also covered software. In its answer ${ }^{53}$ it said that under article 2 of the directive ${ }^{54}$ the term 'product' is defined as 'all movables, with the exception of primary agricultural products - (not having undergone initial processing) - and game, even though incorporated into

\footnotetext{
49 Austrian Law on Civil Liability for Operators of Motor Vehicles and Railways § 5; and Templ (n 41) 12.

50 European product liability laws have been harmonised by Council Directive (EEC) $1985 / 374$ of 25 . July 1985 on the approximation of the laws, regulations and administrative provisions of the Member States concerning liability for defective products [1985] OJ L210/29, amended by Directive (EC) 1999/34 of the European Parliament and of the Council of 10 May 1999 amending Council Directive (EEC) 1985/374 of 25 July 1985 on the approximation of the laws, regulations and administrative provisions of the Member States concerning liability for defective products [1999] OJ L141/20.

51 The same is valid for an importer who introduced products to the European Economic Area. Bundesgesetz vom 21. Jänner 1988 über die Haftung für ein fehlerhaftes Produkt, BGBl 1988/99 aa BGBl I 2001/98 (Austrian Product Liability Law) § 1 par 1 no 1.

52 Templ (n 41) 12-13.

53 Answer to written question No 706/88 to the Commission in [1989] OJ C114/42 114/76.

54 Directive (EEC) 1985/374, see n 50.
} 
another movable or into an immovable'. As a consequence - according to the Commission - the directive applied to software in the same way. ${ }^{55}$ It is therefore safe to assume that software such as an autonomous vehicle's control software can be regarded as a - potentially dangerous - product, thus allowing for the application of product liability law.

Still, this does not answer whether article 1 of the directive, which states that a producer shall be liable for damage caused by a defect in his product, can still be applied in regard to autonomous systems. This question becomes evident after a look at two provisions of the directive. Article 6 defines that 'a product is defective when it does not provide the safety which a person is entitled to expect' and article 7 lit b exempts the producer from liability 'if he proves that it is probable that the defect which caused the damage did not exist at the time when the product was put into circulation'. As autonomous systems - which are controlled by software - are meant to evolve on their own, the producer can therefore hardly be made liable for damages caused by them. There is a definite need for legislative clarification in this matter.

Naturally, these deliberations on liability are based on an Austrian and, by extension, European - legal viewpoint. Any examination of these issues in different cultural and legal surroundings will therefore lead to accordingly varying outcomes. Undoubtedly, questions on liability will be the most pressing issues accompanying the introduction of self-driving vehicles and should therefore be undertaken as soon as possible.

\section{Labour Market}

A major aspect - not to call it a concern - related to artificial intelligence is expressed in regard to possible and likely changes in the labour market. ${ }^{56}$ According to the Robotics Report, the ever-rising number of robots being sold ${ }^{57}$ might not automatically lead to job replacement, but lower-skilled jobs in labour-intensive sectors are likely to be more vulner-

\footnotetext{
55 Christian Horwath, 'Software - ein Produkt?' (Ecolex 2000) 784 wfr.

56 At this point I would like to thank Clemens Zierler from the Institute of Labour Research and Labour Politics of Johannes Kepler University Linz for pointing out the topic's most important sources.

57 Between 2010 and 2014, the average increase in sales of robots stood at 17\% per year and in 2014 sales rose by 29\%, the highest year-on-year increase ever. In 2015, robot sales increased by $15 \%$, again leading to by far the highest number of machines sold ever recorded for one year. The main driver of the growth in 2015 was general industry with an increase of $33 \%$ compared to 2014 , in particular the electronics industry $(+41 \%)$, the metals industry $(+39 \%)$, and the chemical, plastics and rubber industry $(+16 \%)$. Robot sales in the automotive industry increased only moderately in 2015 after a five-year period of continued considerable increase. 'IFR Executive Summary World Robotics 2016 Industrial Robots' (2016) <https://ifr.org/img/uploads/Executive_Summary_WR_Industrial_Robots_20161. pdf $>$ accessed 20 May 2017; Robotics Report (n 1) recital D.
} 
able to automation. There are two sides to this argument, as, on the one hand, increased automation could bring production processes back to the European Union and, at the same time, liberate people from manual monotonous labour, giving them the chance to pursue more meaningful and creative tasks. On the other hand, this trend might end in the widespread replacement of humans by robots without fully replenishing the lost jobs, which raises concerns about the future of employment and the viability of social welfare and security systems. ${ }^{58}$

Overall, the Robotics Report seems to pursue a balanced approach on both the benefits and drawbacks of increased automation, especially in regard to steadily improving artificial intelligence. The possible benefits with regard to efficiency and savings, not only in production and commerce, but also in areas such as transport, medical care, rescue, education, and farming, are likely to be discovered not only by the authors of the report but also by those who for now have to rely on manual labourers and seek to replace them by machines. In some cases, this might make sense for all parties involved, such as in situations where otherwise humans would be exposed to dangerous conditions. ${ }^{59}$ However, simple logical thinking brings to light the obvious benefits for businesses seeking to replace manual labour by machines. While a labourer can work legally for 40 - or a few hours more - a week, his energy and concentration levels may vary during this time, and he can fall sick or become injured. A robot can work tirelessly for all 168 hours a week, does not take breaks, does not get tired, and - most importantly - does not receive any compensation for its work. After the initial investment costs, the employer can rely on the machine and has only to take into account its programming, running, and maintenance costs. For now, programming and maintenance are done by humans, but even these basic skills could potentially soon be taken over by machines. Still, the Report also states that the European Union might face a shortage of up to 825,000 professionals in information and communication technologies by 2020, when around $90 \%$ of jobs will require at least basic digital skills. ${ }^{60}$

These changes have led to debate on how the future of labour might look. One of the major scientific publications in this regard is the Frey and Osborne study, ${ }^{61}$ which assumes that about $47 \%$ of US employment is at risk. ${ }^{62}$ However, this estimate was later relativised through emphasis

\footnotetext{
58 Robotics Report (n 1) recitals J. and K.

59 It is hard to argue against the usage of robots when cleaning up toxically polluted sites or in similarly dangerous situations. See also Robotics Report (n 1) recital E.

60 Robotics Report (n 1) mn 41.

61 Carl Benedikt Frey and Michael A Osborne, 'The Future of Employment: How Susceptible Are Jobs to Computerisation?' (2013) <www.oxfordmartin.ox.ac.uk/downloads/academic/The_Future_of_Employment.pdf> accessed 20 May 2017.

62 ibid, 38.
} 
on the origination of possibly new occupational fields. ${ }^{63}$ While fewer and fewer people are likely to be employed in agriculture and manufacturing industries, a similar amount of people is expected to move to the service sector, compensating for this trend. ${ }^{64}$

However, the only way of knowing which outcomes the influence of better robots equipped with enhanced artificial intelligence will truly have on the job market is by observing the changes as they come. With the likelihood of massive changes to society, the Robotics Report calls for an analysis of different possible scenarios and their consequences on the viability of the social security systems of the Member States. This might require a debate not only on new employment models but also on the sustainability of current tax and social systems. And as a revolution of the labour market could very well have effects on the sufficiency of people's income, the keywords that stand out in the Robotics Report is the cautious mention of the possible introduction of a general basic income. ${ }^{65}$

I had the privilege of being able to discuss some of the main socioeconomic effects of Industry 4.0 at a workshop ${ }^{66}$ at Bournemouth University. As Professor Towse ${ }^{67}$ summarised, the way resources are used obviously influences the distribution of income. If robots replace human labour, the incomes of workers fall. But governments could (and probably will have to) decide to redistribute national income through taxes and welfare payments - or to regulate the use of robots. So the market determines the distribution of income, but in most developed countries the state intervenes to redistribute it. This is an equity goal and requires state - or possibly European Union - intervention in the market economy to achieve it.

\section{Data protection}

While the Robotics Report does not seem to focus primarily on data protection issues, it expresses its awareness of it quite plainly. It states

\footnotetext{
63 Johannes Schweighofer, 'Zur Befreiung des Menschen von mühevoller Arbeit und Plage durch Maschinen, Roboter und Computer - Auswirkungen der Digitalisierung auf die Arbeitsmärkte' (2016) Wirtschaft und Gesellschaft $231 \mathrm{ff}$.

64 'Industrie 4.0 und die Folgen für Arbeitsmarkt und Wirtschaft' (2015) IAB Forschungsbericht 8/2015 8 <http://doku.iab.de/forschungsbericht/2015/fb0815.pdf> accessed 20 May 2017; Martin Risak, 'Arbeitsrecht 4.0' (2017) Journal für Arbeitsrecht und Sozialrecht 14; Rüdiger Krause, Digitalisierung der Arbeitswelt - Herausforderungen und Regelungsbedarf (CH Beck 2016) 22.

65 Robotics Report (n 1) mn 44.

66 Workshop 'Ethics of Intellectual Property Rights: Challenges and Solutions' organised by and held at Bournemouth University's Centre for Intellectual Property Policy \& Management in Bournemouth, United Kingdom, March 2017.

67 Ruth Towse is a Professor in Economics of Creative Industries at Bournemouth University's Centre for Intellectual Property Policy \& Management.
} 
that 'the current insufficient legal framework on data protection and ownership is of great concern due to the (expected massive) flow of data arising from the use of robotics and artificial intelligence'. ${ }^{68}$ Data protection is also seen as an issue the engineers building intelligent machines should take into account, of which they are reminded in the report. According to the 'licence' in its annex, the designers should introduce privacy by design features so as to ensure that private information is kept secure and only used appropriately.

As we have seen in the introduction to Industry 4.0, this phenomenon will also require applications and appliances communicating with each other and with databases without human intervention, thus leading to new privacy concerns. Most recently, the European Union took a big step in data protection by creating the General Data Protection Regulation (GDPR). ${ }^{69}$ The Robotics Report indicates that while the GDPR sets out a legal framework to protect personal data, further aspects of data access and the protection of personal data and privacy might still need to be addressed. I will not cover the GDPR, as it merits a discussion on its own.

\section{Creativity}

Creativity is an inherently human virtue. I would argue that each and every person on this planet is creative - some less, some more - and expresses this characteristic human trait in any conceivable manner, be it music, painting, writing, speech, design, handicraft, cuisine, or problemsolving, to name just a few. Intellectual property rights were created to protect the results of creativity, no matter whether tangible or intangible.

Intellectual property law is the area of law concerned with the recognition and protection of private rights in respect of this expressive and informational subject matter - or better said, intellectual products. ${ }^{70} \mathrm{Gen}$ erally, intellectual property rights are regarded as property rights and as such convey exclusionary rights in respect of certain objects. ${ }^{71}$ Their particular historical development varies greatly from right to right and also from nation to nation ${ }^{72}$ between single intellectual property rights

\footnotetext{
68 Robotics Report (n 1) explanatory statement.

69 fromote988/99 aa BGBl I 2001/98.ok of European Law and Policy, 2017.Regulation (EU) 2016/679 of the European Parliament and of the Council of 27 April 2016 on the protection of natural persons with regard to the processing of personal data and the free movement of such data, and repealing Directive 95/46/EC [2016] OJ L119/1.

70 This definition is a direct quote from Justine Pila and Paul Torremans, European Intellectual Property Law (OUP 2016) 4.

71 ibid, 4.

72 The predominant reason for the territoriality of intellectual property law.
} 
and would merit much more detailed accounts than I could - and should - ever provide here. ${ }^{73}$

Intellectual property rights are essential to the proper functioning of today's economy. Their role must not be underestimated, as they not only provide the tools for the monetisation of creativity but are general driving forces in the promotion of innovation. They allow for the functioning of a competitive market and have long since overtaken most businesses' physical assets in importance.

Faced with the developments in artificial intelligence, the Robotics Report predicts scenarios where machines come up with their own creative output. The Robotics Report calls on the Commission to deal with this issue. In detail, if focuses on two major aspects. Firstly, it asks for a balanced approach to intellectual property rights when applied to hardware and software, which should protect innovation on the one hand and foster innovation on the other. Most importantly, the Robotics Report demands elaboration of the criteria for 'own intellectual creation' for copyrightable works produced by computers or robots. ${ }^{74}$

As of now, only natural persons can obtain copyright, and in that regard such persons are called either 'authors' or 'creators'. It is a wellestablished principle that the creator of a work is the person whose intellectual creation it expresses, the person who has made free and creative choices in creating the work and whose personal mark the work consequently bears. ${ }^{75}$ However, we are now faced with a situation where the determination of original copyright ownership might be problematic. If a computer algorithm composes music or writes a journalistic piece, or if a robot arm decides to grab a paintbrush and create a work of art, we can no longer abide by this definition. There is one jurisdiction in the European Union which - despite its soon to be completed withdrawal from the Union - might serve as a model for a European approach. Section 9 para 3 of the United Kingdom's Copyright, Designs and Patents Act ${ }^{76}$ states that the authorship for computer-generated literary, dramatic, musical, or artistic work should be bestowed upon the person by whom the arrangements necessary for the creation of the work are undertaken. ${ }^{77}$ Apparently, this has yet to be taken into account by the Robotics Report, which does not offer any solutions to the issue of copyright for works created by machines.

\footnotetext{
73 Justine Pila and Paul Torremans, European Intellectual Property Law (OUP 2016) 7ff for a compelling narrative on the historical roots of different intellectual property rights, as well as detailed accounts on more recent developments.

74 Robotics Report (n 1) explanatory statement.

75 Pila and Torremans (n 73) 292.

76 Copyright, Designs and Patents Act 1988, c 48.

77 Burkhard Schafer and others, 'A Fourth Law of Robotics? Copyright and the Law and Ethics of Machine Co-production' (2015) 23(3) Artificial Intelligence and Law 217, 228-229.
} 
In order to shed some light on the topic, I would like to compare the problem to a case I like discussing with my students, which some of you may know as the 'monkey selfie'. Some years ago, photographer David Slater set up a camera on a tripod in a macaque enclosure in Indonesia, deliberately leaving the remote trigger for the camera next to it. His aim was to take photographs of monkeys by providing access to the trigger. One monkey pressed the remote trigger and took several photographs, some of which were unusable, while some others were clear photographs of the macaque. One of them shows a monkey looking straight into the camera, and thus was dubbed the 'monkey selfie'. To keep it short, the photo was distributed online and while Slater claimed copyright, most people argued that he in fact did not obtain it, as he had not taken the photo. The resulting legal proceedings in the United States concluded with a ruling that stated the monkey who took the photographs cannot be declared the copyright owner of the photos. ${ }^{78}$

This decision is based on the US-American copyright system, which differs from the Austrian one. I would argue that in Austria - and the rest of the European Union - the photographer would have obtained copyright. In 2011, the European Court of Justice in the case Painer v Standard Verlags $\mathrm{GmbH}^{79}$ decided that the simplicity of a photo is no bar to its protection by copyright. Any photo, however simple the subject, framing or composition, is protectable by copyright because of the author's free choices that led to the photo. Furthermore, copyright is equal, which means that a 'simple' photo enjoys the same protection as a more sophisticated one.

Article 6 of Directive $116 / 2006^{80}$ says that photographs which are original in the sense that they are the author's own intellectual creation should be protected. No other criteria should be applied to determine their eligibility for protection. Member States may provide for the protection of other photographs. This phrasing ensures a wide scope of protection and would therefore even encompass typical 'point-and-click photos', because the photographer still chose to take them the way he/ she did. As a consequence, if person A hands person B the camera to have her picture taken in the way she wants, person A is the one determining the outcome of the photo and the fact that she did not press the

\footnotetext{
78 'Monkey Selfie Case: Judge Rules Animal Cannot Own his Photo Copyright' The Guardian (London, 7 January 2016) <www.theguardian.com/world/2016/jan/06/monkey-selfiecase-animal-photo-copyright> accessed 20 May 2017.

79 Case C-145/10 Eva-Maria Painer $v$ Standard VerlagsGmbH, Axel Springer AG, Süddeutsche Zeitung GmbH, Spiegel-Verlag Rudolf Augstein GmbH \& Co KG, Verlag M. DuMont Schauberg Expedition der Kölnischen Zeitung GmbH \& Co KG ECLI:EU:C:2011:798.

80 Directive (EC) 2006/116 of the European Parliament and of the Council of 12 December 2006 on the term of protection of copyright and certain related rights [2006] OJ L372/ 12.
} 
shutter release does not prevent her from being regarded as the author of the photograph. Conversely, person B taking the photo - in the way person A wanted to - will not be regarded as such. As a result, even if the photo was taken by a non-person, such as the monkey, I would not doubt the authorship of person A who set up the camera in such a way as to achieve the result she wanted, even if a monkey pressed the shutter.

Of course, if person B chooses to play with, say, the depth of field, composition, framing and makes a photo differently from what person $\mathrm{A}$ would have wanted her to do, person B will have copyright over the photo. ${ }^{81}$ But, in our case, we are not talking about humans. The monkey in the scenario can easily be replaced by a machine operating with artificial intelligence, and the photograph can easily be substituted by any other copyrightable work.

This leads to the conclusion that if a robot creates an - in essence - copyrightable work, it will have to be determined how much influence the person programming or directing the robot had on the outcome. As soon as the robot acts with a degree of autonomy that would consider person $\mathrm{B}$ in our example as the author, the programmer will no longer be regarded as such. Since - as established - only humans can obtain copyright, there is a risk of the work slipping into the public domain. ${ }^{82}$ Consequently, there is a need for clarification of the future of copyright - and potentially other intellectual property rights - when robots start being creative.

As artificial intelligence is already composing music ${ }^{83}-$ which does not even sound bad - and venturing in many other creative fields, from programming ${ }^{84}$ to journalism ${ }^{85}$ my admittedly rather simplistic approach to the topic at hand has recently also been tackled in much more scientific depth. Schafer, Komuves, Zatarain and Diver ${ }^{86}$ rightly point out that

\footnotetext{
81 This would be of limited legal consequence, as I would argue that by taking the photograph, the person could be assumed to implicitly concede to person A full exploitation rights of the photograph, unless stated otherwise.

82 There is no risk, however, that the creation might be regarded as an orphan work, as no one can claim its copyright. The orphan works problem arises where the holder of copyright cannot be identified by a reasonably diligent search, preventing any third party from using the protected work in a manner inconsistent with its copyright. Pila and Torremans (n 73) 246.

83 Alex Marshall, 'From Jingles to Pop Hits, AI Is Music to Some Ears' The New York Times (22 January 2017) <www.nytimes.com/2017/01/22/arts/music/jukedeck-artificial-intelligence-songwriting.html> accessed 20 May 2017.

84 Patrick Caughill, 'Google's AI Is Learning to Make Other AI' (Futurism, 20 January 2017) <https:/ / futurism.com/googles-ai-is-learning-to-make-other-ai/ > accessed 20 May 2017.

85 June Javelosa, 'A Better Journalist? AI Are Better at Predicting Elections Than Humans' (Futurism, 10 November 2016) <https://futurism.com/a-better-jorunalist-ai-are-better-atpredicting-elections-than-humans/> accessed 20 May 2017.

86 Schafer, Komuves, Zatarain and Diver (n 77) 220-221.
} 
the academic discussion regarding computer-generated content currently revolves around what they summarise as 'high art'. They stress, however, that the output created by intelligent machines currently consists of much more mundane, but the nonetheless economically valuable routine production of works, such as short journalistic pieces or business reports. I highly recommend reading their remarkable article ${ }^{87}$ in order to gain insight into an issue I could never hope to solve in the framework of this contribution.

\section{A European Agency}

One of the most enthralling contents of the Robotics Report is the Committee on Legal Affairs calling the Commission to consider the designation of a European Agency for robotics and artificial intelligence. This agency should be created to provide the technical, ethical and regulatory expertise needed to support the relevant public actors, at both Union and Member State level, in their efforts to ensure a timely, ethical and wellinformed response to the new opportunities and challenges, in particular those of a cross-border nature, arising from technological developments in robotics. ${ }^{88}$

The call for a new specialised agency is not surprising. While the Committee only lists the transport sector as a specific example in its rationale for the creation of such an authority, which should come with a proper budget and be staffed with regulators and external technical and ethical experts, a reading of the whole Robotics Report shows all the fields of application it might be responsible for. When speaking of cross-sectoral and multidisciplinary monitoring of robotics-based applications, the Robotics Report demonstratively lists areas such as autonomous vehicles, drones, care robots, medical robots, or human repair and enhancement as major industries that might or will be affected by robotics and artificial intelligence. It is apparent that their impact will bring important questions that range from ethical principles, standardisation, safety and security, liability, to flow of data. In addition, this agency could and should approach issues such as research and innovation, education and employment, environmental impact, and - as a major driving force of the economy - intellectual property rights.

87 Furthermore, another recent article specifically covering similar issues in the context of patent law stands out. Erica Fraser, 'Computers as Inventors - Legal and Policy Implications of Artificial Intelligence on Patent Law' (2016) 13(3) Scripted 305.

88 Robotics Report (n 1) mn 15-17. 


\section{Conclusion}

I am fully aware that this article touches on a variety of subjects, as it was my intention to show the abundance of issues that the everincreasing importance of Industry 4.0 in the near future will undoubtedly bring. For one thing, artificial intelligence is steadily taking over the labour market. Its implementation will inevitably lead to challenges for the low-skilled workforce - especially in assembly-line work, as well as in the transport sector - and sparks a call for a universal basic income.

Furthermore, intelligent machines in the form of self-driving vehicles may soon be a common sight on our roads, but not until policy makers have agreed upon national and international liability standards. Due to the absence of a human vehicle operator, new approaches will most probably have to be based on strict liability paired with product liability, as trends in this industry have already shown.

Data protection will become more of an issue than it is already. While many basic questions with regard to this topic have already become an issue in the era of the internet and e-commerce, further aspects of data ownership and the protection of personal data and privacy are still uncertain. One of the main concerns will arise from the widespread appearance of self-driving vehicles relying on massive amounts of data used for autonomous navigation.

Artificial intelligence will also increasingly play a role in other domains once exclusively reserved for humans. Machines are already writing, painting, and composing, which calls for a new definition of creativity. One of the questions in this regard will be the ownership of intellectual creations, and whether to link them to human or artificial minds. For now, the level of influence a human has on the creative work's outcome might be the most consequential link, but increasing autonomy in creative machines might soon make this link obsolete.

As stated above, reading the Robotics Report at times feels like being immersed in a science-fiction novel. However, we have already arrived in a world that would some years ago have felt like a figment of some scientist's imagination. The impressive variety of technological developments in the fields of robotics and artificial intelligence will undoubtedly have a great impact on society. A close look at the European Parliament's approach to these already occurring and upcoming changes not only shows its awareness of their revolutionary aspect but also demonstrates that the call for a new kind of specialised agency has its merits. For now, the European Union policy makers are ahead of the game. By setting up an agency which specialises in questions of robotics and artificial intelligence, it will also be able to keep up with it. 